\title{
Article \\ Energy Efficiency Optimization for Machining of Wood Plastic Composite
}

\author{
Zhaolong Zhu ${ }^{1,2}$, Dietrich Buck ${ }^{3}$, Xiaolei Guo ${ }^{1,4, * \mathbb{C}}$, Xianqing Xiong ${ }^{1,2}$, Wei $\mathrm{Xu}^{1,2}$ and Pingxiang Cao ${ }^{4}$ \\ 1 Co-Innovation Center of Efficient Processing and Utilization of Forest Resources, Nanjing Forestry University, \\ Nanjing 210037, China; zhuzhaolong@njfu.edu.cn (Z.Z.); xiongxianqing@njfu.edu.cn (X.X.); \\ xuwei@njfu.edu.cn (W.X.) \\ 2 College of Furnishings and Industrial Design, Nanjing Forestry University, Nanjing 210037, China \\ 3 Wood Science and Engineering, Luleå University of Technology, 93187 Skellefteå, Sweden; \\ dietrich.buck@ltu.se \\ 4 College of Materials Science and Engineering, Nanjing Forestry University, Nanjing 210037, China; \\ caopx@njfu.com.cn \\ * Correspondence: xiaolei.guo@njfu.edu.cn
}

Citation: Zhu, Z.; Buck, D.; Guo, X.; Xiong, X.; Xu, W.; Cao, P. Energy

Efficiency Optimization for

Machining of Wood Plastic

Composite. Machines 2022, 10, 104.

https://doi.org/10.3390/

machines10020104

Received: 6 January 2022

Accepted: 26 January 2022

Published: 28 January 2022

Publisher's Note: MDPI stays neutral with regard to jurisdictional claims in published maps and institutional affiliations.

Copyright: (c) 2022 by the authors. Licensee MDPI, Basel, Switzerland. This article is an open access article distributed under the terms and conditions of the Creative Commons Attribution (CC BY) license (https:// creativecommons.org/licenses/by/ $4.0 /)$.

\begin{abstract}
Enhancing energy efficiency is the key to realizing green manufacturing. One major area of interest in this regard is the improvement of energy efficiency of machine tools during the production of building materials. This project focuses on energy efficiency during the spiral milling of wood plastic composites. To this end, a response surface method was adopted to develop a model and establish the relationship between energy efficiency and milling conditions. Analysis of variance based on individual factors as well as two-factor interactions was performed to gauge their effects on energy efficiency. It was found that milling depth was positively correlated to power efficiency, while spiral angle and feed per tooth displayed non-monotonic behavior. An attempt was made to predict milling conditions that will yield the greatest material removal rate and power efficiency. For wood plastic composites subjected to up-milling, it was determined that a feed per tooth of $0.1 \mathrm{~mm}$, milling depth of $1.5 \mathrm{~mm}$, and spiral angle of $70^{\circ}$ were ideal. Considering the potential improvements in energy efficiency and surface quality that these process parameters will bring, it is strongly recommended for use in the industrial machining of wood plastic composites.
\end{abstract}

Keywords: green manufacturing; energy efficiency; spiral up-milling; wood-based material; optimization

\section{Introduction}

The manufacturing industry has advanced at a rapid pace and with it, high-performance manufacturing techniques $\mathrm{h}$ become critical to attain sustainable development [1], improve power [2] and processing efficiency [3], and increase machining quality [4]. The two main factors that influence machining tool energy consumption and product surface quality are cutting parameters and tool geometries [5].

Therefore, it is not surprising that many research efforts over the years have investigated the optimization of cutting parameters during machining, such as cutting force, tool wear, power, and quality [6,7]. Dong et al. [8] studied the effects of tool wear on cutting power and found that not only did cutting power increase with tool wear, but changes in the tool's cutting power indicated wear conditions in real time. Cao et al. [9] adopted an orthogonal design to optimize parameters and reduce energy consumption and surface roughness of milled glass magnesium boards. Subsequently, Camposeco-Negrete [10] took the analysis of variance (ANOVA) approach to minimize cutting energy for the turning of alloy AISI 6061 T6. Recently, Zhu et al. [11,12] also adopted a response surface method (RSM) to minimize cutting force, reduce surface roughness, and maximize removed volume in the milling of a stone-plastic composite. Despite the differences in approach, these 
optimized cutting conditions have led to significant reductions in energy consumption while simultaneously improving surface quality.

Wood-plastic composite (WPC), as the name suggests, is composed of wood fibers and plastics, and prepared through a hot-pressing procedure $[13,14]$. Owing to its origins from waste resources combined with its inherent waterproof characteristics and dimensional stability, WPC is widely regarded as a novel green material that is poised to revolutionize the global flooring and packaging industries [15-17]. Statistics from the China Forestry Industry Association indicate that WPC flooring sales reached almost 74 million $\mathrm{m}^{2}$ in 2020, with a growth rate of $5.71 \%$ [18]. To meet this unprecedented market demand, WPC needs to be dimensionally processed using cutters to achieve the specific dimensions and surface smoothness levels of the final product.

A review of literature covering WPC machining revealed that most recent research efforts focused on specific aspects of machining, such as cutting force, temperature, and chip deformation [19-22]. To the best of our knowledge, there is no study investigating energy efficiency and surface appearance when it comes to WPC machining. These are key factors that can bring about significant benefits for large-scale production of WPC and material quality control. As such, this research aims to optimize milling conditions to facilitate energy efficient WPC machining without compromising surface appearance. In particular, the impact of different spiral cutters on energy efficiency is assessed through response surface methodology (RSM) and modeled to predict high-performance milling conditions.

\section{Materials and Methods}

\subsection{Cutters and Workpieces}

Polycrystalline diamond (PCD) cutter with six teeth and a diameter of $140 \mathrm{~mm}$ was the cutting tool of choice for this project (Figure 1a). The PCD was made from diamond powder and cobalt/nickel-based binders sintered at temperatures of $1000-2000{ }^{\circ} \mathrm{C}$ and pressures of 5000-10000 MPa, followed by welding onto the cutter body with carbide cement. The tool angles used and its material properties are listed in Table 1. The WPC used in this study was made from a mixture of wood fiber and polyethylene at a ratio of 2:3 (Figure 1b). Dimensions of the WPC workpieces were set to $500 \mathrm{~mm}$ length $\times 100 \mathrm{~mm}$ width $\times 5 \mathrm{~mm}$ thickness, and its material properties are listed in Table 2.

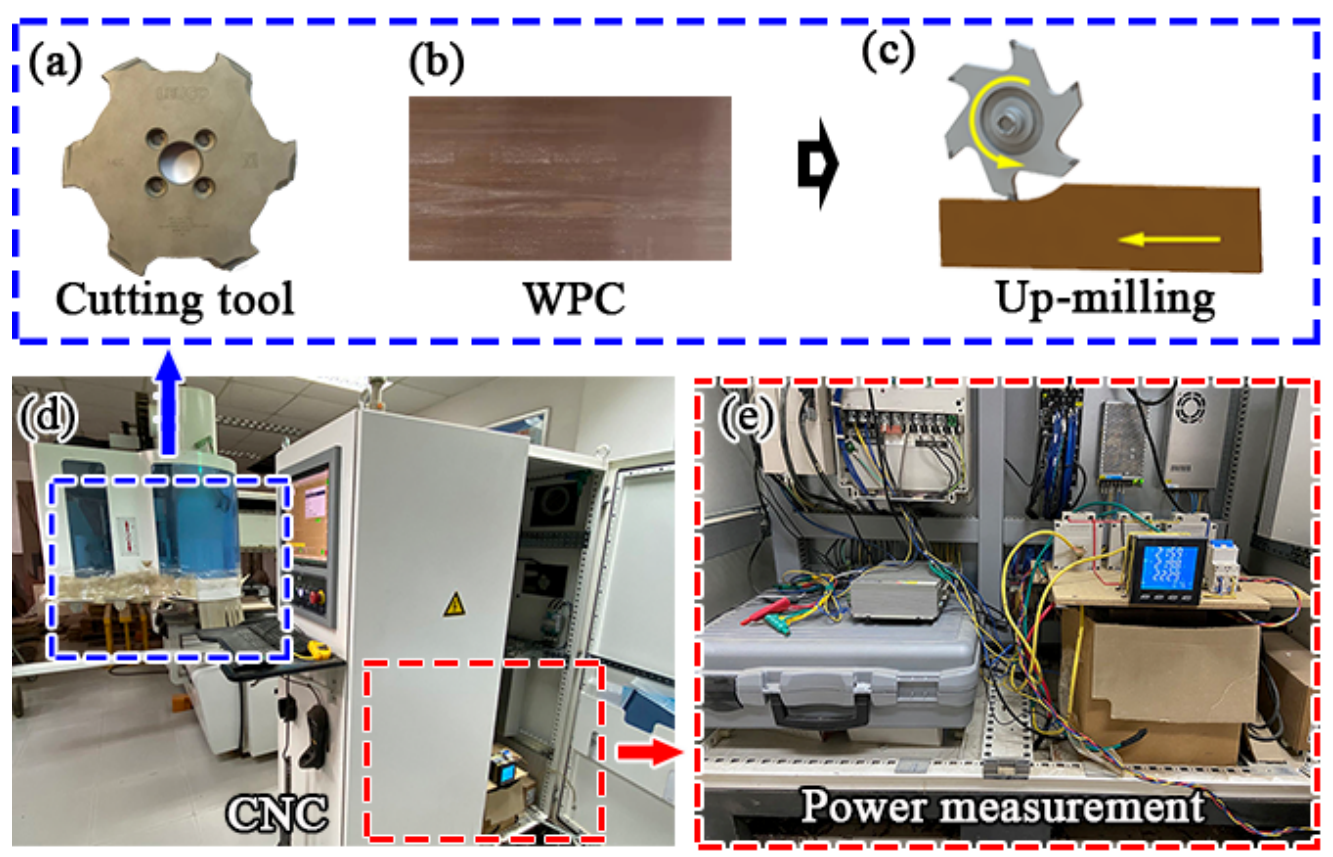

Figure 1. Experiment setup for WPC milling. (a) Photograph of PCD, (b) photograph of WPC workpiece, (c) schematic illustration of up-milling, (d) photograph showing milling section linked with $\mathrm{CNC}$, and (e) closer view of the power measurement setup. 
Table 1. Tool settings and material properties of Diamond Spiral Cutters.

\begin{tabular}{cccccc}
\hline & \multicolumn{3}{c}{ Tool Angles } & Material Properties \\
\cline { 2 - 4 } No. & $\begin{array}{c}\text { Spiral } \\
\text { Angle }\end{array}$ & $\begin{array}{c}\text { Rake } \\
\text { Angle }\end{array}$ & Wedge Angle & Coefficient of Thermal Expansion & $\begin{array}{c}\text { Thermal } \\
\text { Conductivity }\end{array}$ \\
\hline 1 & $54^{\circ}$ & $10^{\circ}$ & $72^{\circ}$ & & \\
Hardness
\end{tabular}

Table 2. Material Properties of WPC.

\begin{tabular}{ccccc}
\hline Workpiece & Density & Bending Strength & Tensile Strength & Modulus of Elasticity \\
\hline WPC & $1.45 \mathrm{~g} / \mathrm{cm}^{3}$ & $4.69 \mathrm{MPa}$ & $26.21 \mathrm{MPa}$ & $4270 \mathrm{MPa}$ \\
\hline
\end{tabular}

\subsection{Experimental Setup}

A CNC machine (MGK01, Nanxing Machinery Co., Ltd., Dongguan, China) with an $8.1 \mathrm{~kW}$ machine engine, maximum feed rate of $50 \mathrm{~m} / \mathrm{min}$, and spindle speed of 24,000 rpm in dry conditions was used to perform up-milling on the WPC workpieces (Figure 1c). Workpieces were fixed on the working plane of the machine using vacuum adsorption. Dynamic spindle power signal was acquired during machining using a three-phase power analyzer (AN87300, Ainuo Co., Ltd., Jinan, China) with a sampling frequency of $50 \mathrm{KHz}$.

\subsection{Experimental Methods}

Response surface methodology (RSM), a mathematical and statistical method for modeling and analyzing relationships between explanatory variables and response variables, was adopted in this work [23-25]. Specifically, Box-Behnken and Central-Composite experimental design techniques were used to develop mathematical models to predict power efficiency of the WPC milling process. Table 3 shows the experimental factor levels chosen based on industrial WPC manufacturing processes parameters, namely feed per tooth $f_{z}$, milling depth $a_{p}$, and spiral angle $\omega$. The feed per tooth value was obtained from Equation (1) as follows [26]:

$$
f_{z}=\frac{1000 V_{f}}{n \cdot z}
$$

where $V_{f}$ represents a feed rate of $10 \mathrm{~m} / \mathrm{min}, z$ stands for the tooth number (6), and $n$ denotes the spindle speeds $(11,111,13,333$, and 16,666 r/min).

Table 3. Experimental Factor Levels.

\begin{tabular}{cccc}
\hline Factor Level & $f_{\mathbf{z}}$ & $\boldsymbol{a}_{\boldsymbol{p}}$ & $\omega$ \\
\hline 1 & $0.10 \mathrm{~mm}$ & $0.5 \mathrm{~mm}$ & $54^{\circ}$ \\
2 & $0.125 \mathrm{~mm}$ & $1.0 \mathrm{~mm}$ & $62^{\circ}$ \\
3 & $0.15 \mathrm{~mm}$ & $1.5 \mathrm{~mm}$ & $70^{\circ}$ \\
\hline
\end{tabular}

The Box-Behnken experimental design for RSM yielded 17 combinations of feed per tooth $f_{z}$, milling depth $a_{p}$, and spiral angle $\omega$ as listed in Table 4. Subsequently, each of these cutting combinations were repeated five times, maintaining a constant cutting width of $5 \mathrm{~mm}$. The tool's response function was expressed as Equation (2) [27]:

$$
R=\alpha_{0}+\sum_{i=1}^{k} \alpha_{i} \beta_{i}+\sum_{i j}^{k} \alpha_{i j} \beta_{i} \beta_{j}+\sum_{i=1}^{k} \alpha_{i i} \beta_{i}^{2}
$$


where $R$ stands for the response result, namely, the power efficiency $\eta, \alpha_{0}$ is a fixed term, $\alpha_{i}$ is the coefficient of the linear term, $\alpha_{i j}$ and $\alpha_{i i}$ denote the coefficients of the linear and quadratic terms, respectively, and $\beta_{i}$ represents the response variables.

Table 4. Box-Behnken Experimental Design.

\begin{tabular}{ccccc}
\hline No. & $f_{\mathbf{z}}(\mathbf{m m})$ & $\boldsymbol{a}_{\boldsymbol{p}}(\mathbf{m m})$ & $\boldsymbol{\omega}\left(\mathbf{(}^{\circ}\right)$ & $\boldsymbol{\eta}(\mathbf{\%})$ \\
\hline 1 & 0.10 & 1.0 & 54 & 32.7 \\
2 & 0.10 & 0.5 & 62 & 25.5 \\
3 & 0.10 & 1.0 & 70 & 45 \\
4 & 0.10 & 1.5 & 62 & 58.2 \\
5 & 0.125 & 1.5 & 70 & 62.4 \\
6 & 0.125 & 0.5 & 54 & 20.3 \\
7 & 0.125 & 1.5 & 54 & 46.9 \\
8 & 0.125 & 0.5 & 70 & 25.4 \\
9 & 0.125 & 1.0 & 62 & 39.2 \\
10 & 0.125 & 1.0 & 62 & 40.1 \\
11 & 0.125 & 1.0 & 62 & 38.9 \\
12 & 0.125 & 1.0 & 62 & 39.2 \\
13 & 0.125 & 1.0 & 62 & 39.8 \\
14 & 0.15 & 1.5 & 62 & 53.6 \\
15 & 0.15 & 1.0 & 54 & 39.6 \\
16 & 0.15 & 1.0 & 70 & 37.6 \\
17 & 0.15 & 0.5 & 62 & 23.0 \\
\hline
\end{tabular}

\section{Results and Discussion}

To maximize the economic benefits of industrial machining of WPC, manufacturers are prioritizing processing and energy efficiency without compromising product quality $[28,29]$. Among the various factors that are important in this regard, the material removal rate is one of the most crucial evaluation indexes for processing efficiency. As such, the ideal WPC milling process must facilitate the highest material removal rate using the least energy possible, while ensuring an excellent surface finish. This section looks into the tool factors that contribute most towards cutting power, the dynamic power data acquisition process, and modeling to predict ideal milling conditions for WPC.

\subsection{Dynamic Characteristics of Cutting Power}

When it comes to machining, cutting power generates two effects: (i) tool rotation and (ii) resistance during removal of material by the tool [30-32]. Understanding how cutting power fluctuates in real time can lead to optimized cutting processes that minimize energy loss and prolong tool life. The dynamic changes in cutting power during the WPC milling process performed in this study are shown in Figure 2. The specific states being monitored were the start and standby states of the machine tool, start state of the spindle motor, the unloading state of the machine tool, and lastly, the cutting state. It is worth noting that for tool clamping, power consumption was between the start and standby state levels $(0-50 \mathrm{~W})$. The sharp rise in dynamic power corresponding to the start state of the spindle motor is attributed to the increase in kinetic energy of the cutter when accelerating to a set speed from standby levels. The unloading state, which occurs around $26 \mathrm{~s}$ into the milling process, results in stable dynamic power, provided the cutter rotation speed is kept constant. When the cutter contacts the WPC workpiece, frictional resistance caused by removal of unwanted material from the workpiece by the cutter tool results in an increase in dynamic power. Once the cutting process is complete, dynamic power values reduce gradually and eventually drop down to standby levels. 


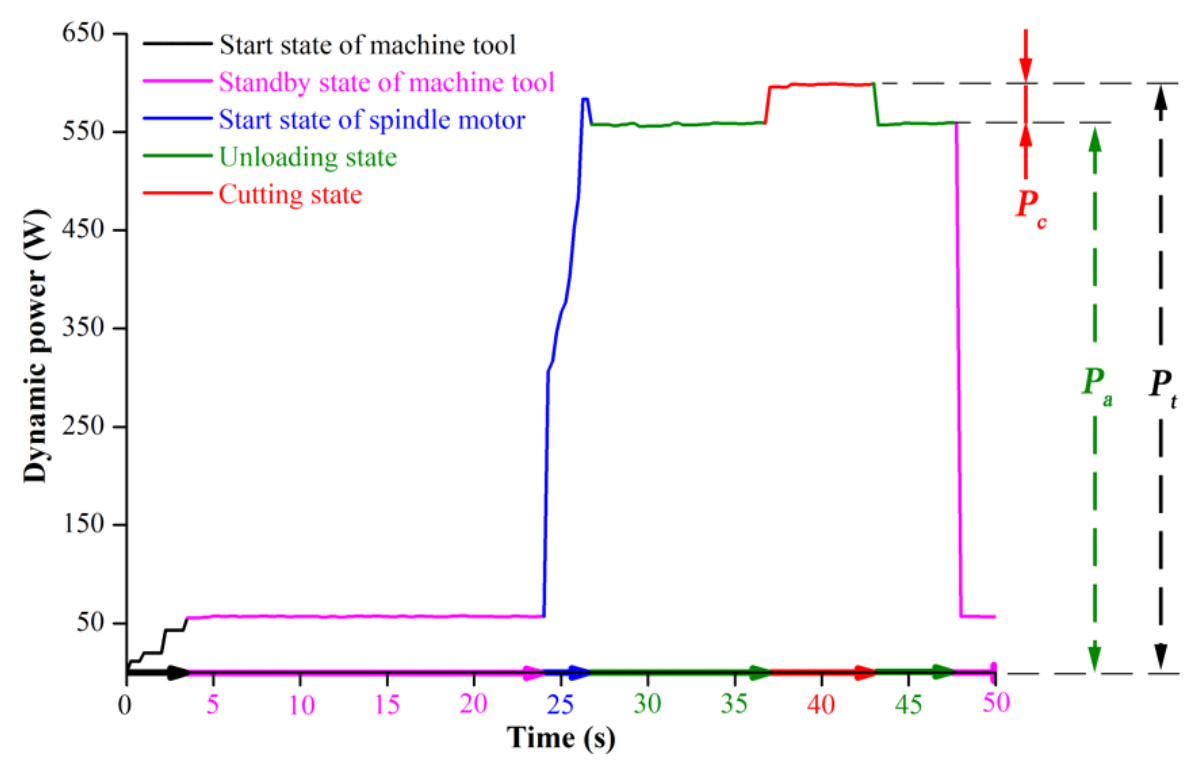

Figure 2. Dynamic power during WPC milling.

According to prior research on cutting power carried out by Barcík et al. [29] and Mandic et al. [32], the levels of cutting power are determined from cutting volume and workpiece properties, amongst others. Importantly, power efficiency stood out as one of the most representative indexes for energy consumption and machining in the industrial machining of materials. Therefore, the power efficiency for WPC workpieces subjected to milling in this study was investigated further using Equations (3) and (4):

$$
\begin{gathered}
P_{c}=P_{t}-P_{a} \\
\eta=\frac{E_{c}}{E_{t}}=\frac{\int_{t_{1}}^{t_{2}} P_{c} d t}{\int_{t_{1}}^{t_{2}} P_{t} d t}=\frac{P_{c}}{P_{t}}
\end{gathered}
$$

where $P_{c}$ denotes cutting power, $P_{t}$ is the total spindle power, $P_{a}$ is the unloading cutting power, $E_{c}$ represents the cutting energy consumption, $E_{t}$ is the total energy consumption, and $\eta$ is the power efficiency.

\subsection{Developed Mathematical Model of Power Efficiency}

Power efficiency results derived from Table 3 , which lists the feed per tooth $\left(f_{z}\right)$, milling depth $\left(a_{p}\right)$, and spiral angle $(\omega)$ was used to build the quadratic model of power efficiency expressed as Equation (5).

$$
\begin{gathered}
\eta=-173.30+992.25 f_{z}-5.97 a_{p}+4.04 \omega-42.00 f_{z} \cdot a_{p} \\
-17.88 f_{z} \cdot \omega+0.70 a_{p} \cdot \omega+488.00 f_{z}{ }^{2}+1.32 a_{p}{ }^{2}-0.02 \omega^{2}
\end{gathered}
$$

A plot between the experimentally obtained values of power efficiency $\eta$ and the predicted values based on this model is shown in Figure 3. Importantly, the $R^{2}$ and $A d j-R^{2}$ values were found to be $99.1 \%$ and $98 \%$, respectively, which confirms that the predicted values of $\eta$ were remarkably close to the actual values verified experimentally. The low coefficient of variation (C.V.) value of $4.3 \%$ further confirms the excellent model fit and lack of skew in the data. Thus, it is reasonable to expect this model to predict power efficiency accurately towards optimizing WPC milling. 


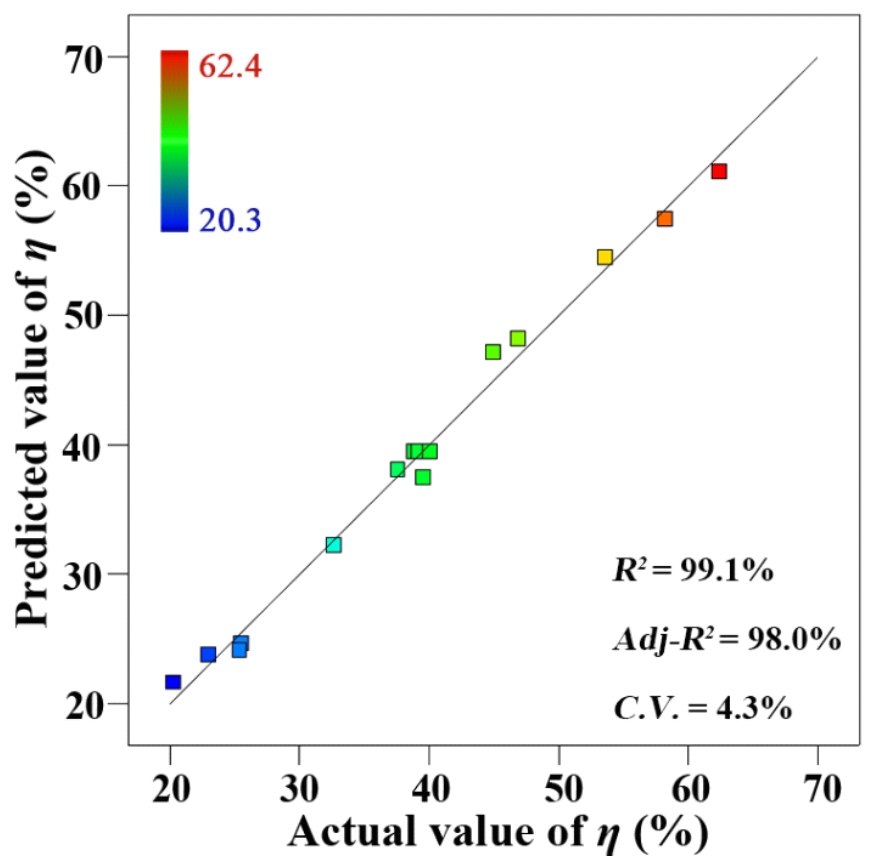

Figure 3. Actual and predicted values of power efficiency.

\subsection{Analysis of Variance for Power Efficiency}

The analysis of variance (ANOVA) is a means to predict the statistical significance of each factor in a study. As such, it provides a straightforward route to estimate the significance of milling depth $\left(a_{p}\right)$, spiral angle $(\omega)$, feed per tooth $\left(f_{z}\right)$, and combinations thereof on the power efficiency $(\eta)$ of the cutting tool. With an F-value of 87.84 and a corresponding $p$-value less than 0.05 , it was confirmed that the developed power efficiency model is statistically fit for the data at hand. Typically, a $p$-value less than 0.05 can be seen as significant; otherwise, it is considered insignificant [23,26]. The ANOVA results pertaining to power efficiency listed in Table 5 suggests that the milling depth $\left(a_{p}\right)$, spiral angle $(\omega)$, interaction terms of feed per tooth and spiral angle $\left(f_{\mathrm{z}} \times \omega\right)$ and milling depth and spiral angle $\left(a_{p} \times \omega\right)$ make statistically significant contributions $(p<0.05)$ to power efficiency. Of these, milling depth delivered the greatest impact on power efficiency with a contribution of $89.72 \%$. $\omega, f_{\mathrm{z}} \times \omega$, and $a_{p} \times \omega$ contributed significantly less with values of $5.32 \%, 2.28 \%$, and $1.21 \%$, respectively. All the remaining factors considered were deemed statistically insignificant, and thus, are not expected to influence power efficiency of the cutting tool.

Table 5. ANOVA Results of Power Efficiency.

\begin{tabular}{cccccccc}
\hline Source & Sum of Squares & \% Cont. & DF & Mean Square & F-Value & $p$-Value & Remark \\
\hline$\eta$ & 2223.79 & $/$ & 9 & 7.22 & 87.84 & $<0.0001$ & Significant \\
$f_{\mathrm{z}}$ & 7.22 & 0.32 & 1 & 2012.95 & 2.57 & 0.1532 & Insignificant \\
$a_{p}$ & 2012.95 & 89.72 & 1 & 119.35 & 715.64 & $<0.0001$ & Significant \\
$\omega$ & 119.35 & 5.32 & 1 & 1.10 & 42.43 & 0.0003 & Significant \\
$f_{\mathrm{z}} \times a_{p}$ & 1.10 & 0.05 & 1 & 51.12 & 0.39 & 0.5511 & Insignificant \\
$f_{\mathrm{z}} \times \omega$ & 51.12 & 2.28 & 1 & 27.04 & 18.18 & 0.0037 & Significant \\
$a_{p} \times \omega$ & 27.04 & 1.21 & 1 & 0.39 & 9.61 & 0.0173 & Significant \\
$f_{\mathrm{z}}^{2}$ & 0.39 & 0.02 & 1 & 0.46 & 0.14 & 0.7200 & Insignificant \\
$a_{p}^{2}$ & 0.46 & 0.02 & 1 & 4.38 & 0.16 & 0.6984 & Insignificant \\
$\omega^{2}$ & 4.38 & 0.20 & 1 & 7.22 & 1.56 & 0.2521 & Insignificant \\
Residual & 19.69 & 0.88 & 7 & 2.81 & - & - & - \\
Total & 2243.48 & 100 & 16 & - & & - & - \\
\hline
\end{tabular}




\subsection{Effects of Milling Variables on Power Efficiency}

Correlation, which is the extent to which two variables are linearly related, is a powerful tool to assess how different milling conditions influence power efficiency. As can be seen in Figure 4, power efficiency is positively related to milling depth, while both feed per tooth and spiral angle exhibit non-monotonic behavior. In fact, an increased milling depth and decreased feed per tooth enhance the power efficiency when WPC is machined with cutters at a $62^{\circ}$ spiral angle. While power efficiency shows a moderate increase at $70^{\circ}$ spiral angle when the feed per tooth is decreased, the same cannot be said for WPC machined at a $54^{\circ}$ spiral angle and a milling depth of $1.0 \mathrm{~mm}$ (Figure $4 \mathrm{~b}$ ). These contrasting trends suggest that optimal milling conditions for WPC are low feed per tooth, high milling depth, and large spiral angle or, high feed per tooth, high milling depth, and small spiral angle.

(a)
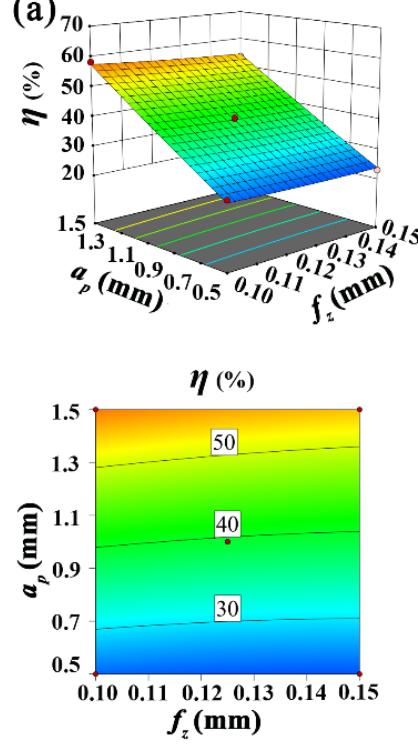

(b)
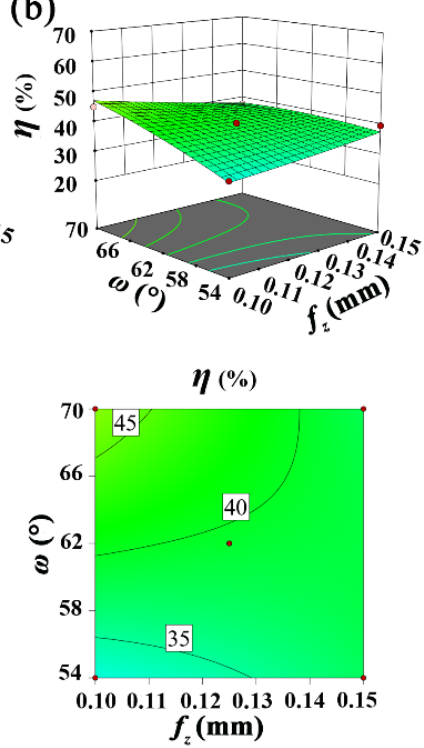

(c)
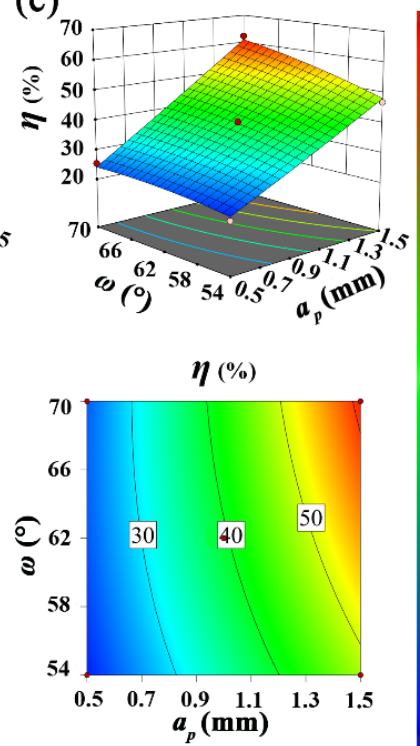

Figure 4. 3D response surface and contours of two-level interactions on power efficiency, namely, (a) milling depth and feed per tooth, (b) spiral angle and feed per tooth, and (c) spiral angle and milling depth.

\subsection{Optimization and Verification for High-Performance Machining}

As shown in Figure 5, spiral up-milling is an intermittent cutting process where the cutting edges of the blades cut into and out of the workpiece in sequence. Due to the inclination angle of each cutting edge, namely, the spiral angle when the cutting edge cuts into the workpiece, the chip width gradually increases from zero to the maximum. As the cutting process continues, the chip width decreases to zero until the rake face removes all of the unwanted material. These dynamic changes in chip width during the spiral up-milling process are expressed mathematically as follows:

$$
\begin{gathered}
d b=\frac{\frac{D}{2} d \varphi}{\sin \omega}=\frac{D}{2 \sin \omega} d \varphi \\
b=\int_{\varphi_{2}}^{\varphi_{1}} \frac{D}{2 \sin \omega} \mathrm{d} \varphi=\frac{D\left(\varphi_{1}-\varphi_{2}\right)}{2 \sin \omega}=\frac{D \cdot \varphi_{x}}{2 \sin \omega}
\end{gathered}
$$

where $b$ describes the chip width in $\mathrm{mm}, D$ denotes the tool diameter $(140 \mathrm{~mm})$, and $\varphi$ is the rotating angle in degrees $\left(^{\circ}\right)$. 


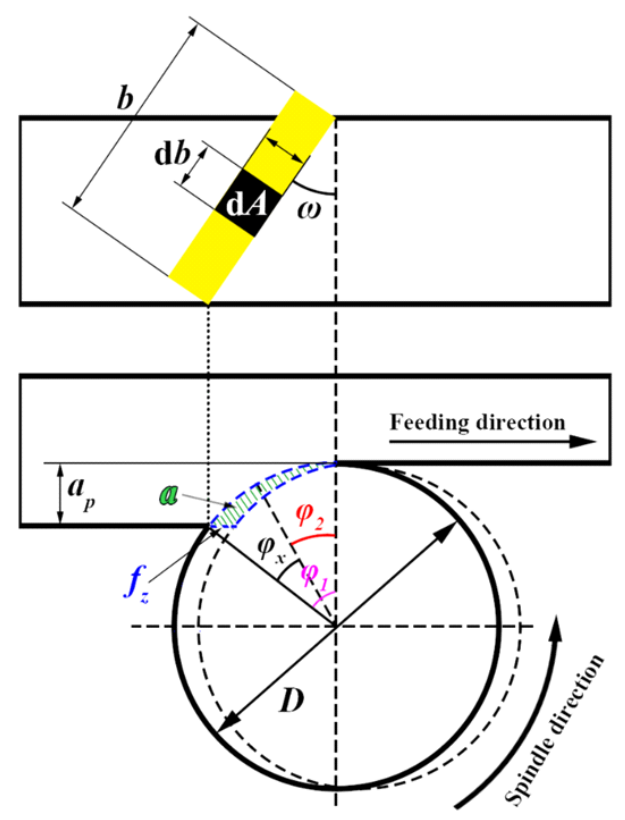

Figure 5. Material removal volume during spiral up-milling.

As mentioned earlier, the machining method chosen for this research was up-milling. This technique involves the cutting edge biting into the workpiece, causing the cutting thickness to increase from zero to maximum until the chip is removed from the workpiece. Thus, the cross-sectional area of the removed chip can be calculated via integration as:

$$
\begin{gathered}
\mathrm{d} A=a \cdot \mathrm{d} b=\frac{D \cdot f_{z}}{2 \sin \omega} \cdot \sin \varphi_{x} \cdot \mathrm{d} \varphi_{x} \\
A=\int_{\varphi_{2}}^{\varphi_{1}} \frac{D \cdot f_{z}}{2 \sin \omega} \cdot \sin \varphi_{x} \cdot \mathrm{d} \varphi_{x}=\frac{D \cdot f_{z}}{2 \sin \omega}\left(\cos \varphi_{2}-\cos \varphi_{1}\right)
\end{gathered}
$$

where $A$ is the cross-sectional area of the chip and $a$ denotes the cutting thickness. Further, the volume of chip removed per tooth and the material removal rate are calculated from Equations (10)-(12) [8]:

$$
\begin{gathered}
V=A \cdot \int_{0}^{\varphi} \frac{D}{2} \cdot d \varphi=\frac{D^{2} \cdot a_{p}}{4 \sin \omega} \cdot \varphi(1-\cos \varphi) \\
\cos \varphi=1-\frac{2 a_{p}}{D} \\
M R R=\frac{V \cdot f}{f_{z}}=\frac{D^{2} \cdot f}{4 \sin \omega} \cdot \varphi(1-\cos \varphi)=\frac{D \cdot f \cdot a_{p}}{2 \sin \omega} \cdot \arccos \left(1-\frac{2 a_{p}}{D}\right)
\end{gathered}
$$

where $V$ represents the removed volume of chip per tooth in $\mathrm{mm}^{3}$, and $M R R$ stands for the material removal rate in $\mathrm{mm}^{3} / \mathrm{s}$.

According to Equations (8)-(12), the material removal rate is primarily determined from the feed rate, tool diameter, spiral angle, and milling width during the up-milling process. In this project, the tool diameter and feed rate were set as quantitative measures, while the material removal rate was a function of the milling parameters represented in Figure 6. It is worth noting that the material removal rate increases with an increase in the milling depth and a decrease in the spiral angle. To confirm versatility of the developed model, optimal milling conditions were obtained for multiple objects to achieve the highest processing and energy efficiency, while ensuring the best possible surface quality. 


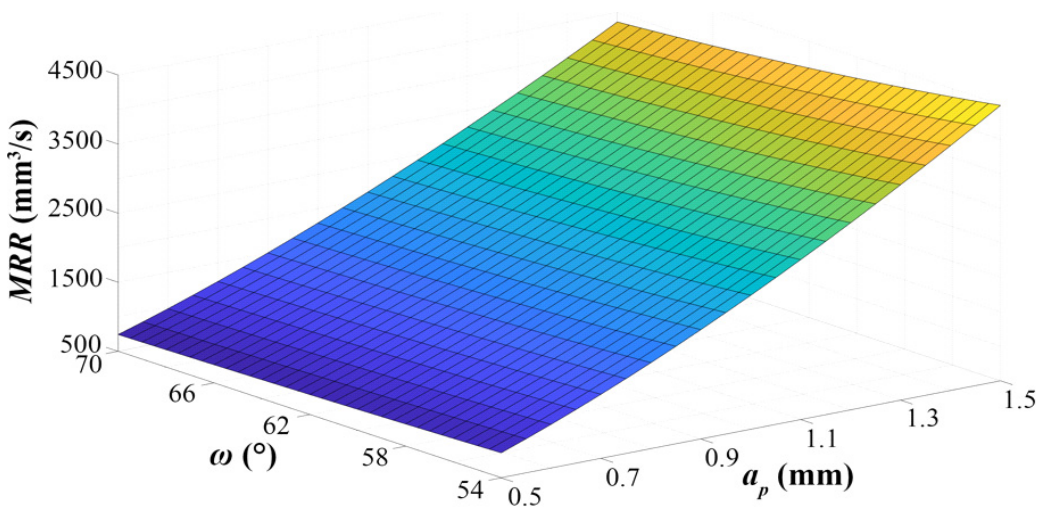

Figure 6. Material removal rate as a function of milling parameters.

The results from the multi-optimization RSM process to determine the highest material removal rate and power efficiency for WPC machining are shown in Table 6. It was evident that both the material removal rate and power efficiency were distinctly higher for milling condition I as opposed to II. Moreover, the surface quality was also significantly better for the former. Nevertheless, for both milling conditions, the measured power efficiency was close to the predicted value, confirming that the proposed model from this study can guide the optimization of cutting processes for power efficiency. Within the experimental limits of this study, the optimized milling conditions for WPC were determined to be a feed per tooth of $0.1 \mathrm{~mm}$, milling depth of $1.5 \mathrm{~mm}$, and spiral angle of $70^{\circ}$. Use of these specific milling conditions for industrial machining of WPC can maximize power efficiency, ensure good surface quality, and yield significant economic benefits.

Table 6. Optimization and Verification Results.

\begin{tabular}{ccccccccc}
\hline No. & $f_{\mathrm{z}}(\mathbf{m m})$ & $a_{\boldsymbol{p}}(\mathrm{mm})$ & $\omega\left({ }^{\circ}\right)$ & $\operatorname{MRR}\left(\mathrm{mm}^{2} / \mathbf{s}\right)$ & $\boldsymbol{R}_{\mathrm{a}}(\mu \mathrm{m})$ & Actual- $\boldsymbol{\eta}$ & Predicted- $\eta$ & Error \\
\hline I & 0.1 & 1.5 & 70 & 3862.3 & 1.9 & $63.0 \%$ & $66.4 \%$ & $-5.1 \%$ \\
II & 0.15 & 1.5 & 62 & 4110.5 & 2.1 & $58.2 \%$ & $54.5 \%$ & $6.8 \%$ \\
\hline
\end{tabular}

\section{Conclusions}

Enhancing energy efficiency is the key to realizing green manufacturing. This study demonstrates the improvement in energy efficiency of machine tools during the production of building materials based on WPC. RSM was employed for optimizing the power efficiency of up-milling WPC using rotating cutters. A mathematical model was also developed to predict the power efficiency of the milling process and was subsequently verified to determine optimal milling conditions. The main conclusions are as follows:

(1) Power efficiency is positively correlated with milling depth, while changes in power efficiency exhibited non-monotonic trends for different feed per tooth values and spiral angles.

(2) Only the factors of milling depth, spiral angle, and interaction terms of $f_{z} \times \omega$ and $a_{p} \times \omega$ had a statistically significant influence on the power efficiency. In particular, milling depth contributed most towards power efficiency $(89.72 \%)$, followed by feed per tooth $(2.28 \%)$ and spiral angle $(1.21 \%)$. Therefore, optimizing milling depth is crucial to improve energy efficiency.

(3) Within the experimental limits of this work, the optimal milling conditions for WPC in terms of processing ease, energy efficiency, and surface finish were determined to be as follows: feed per tooth of $0.1 \mathrm{~mm}$, milling depth of $1.5 \mathrm{~mm}$, and spiral angle of $70^{\circ}$. It is strongly recommended that these process parameters be applied towards the machining of WPC in industry to maximize power efficiency, surface quality, and economic benefits. 


\begin{abstract}
Author Contributions: Z.Z. contributed to project administration, experimental design, analysis and discussion of the data, and writing the paper. D.B. was involved in laboratory experiments, data collection, analysis and discussion of the data, and editing the paper. X.G. contributed to laboratory experiments, data collection, and review of the paper. X.X. was involved in laboratory experiments, data collection, and supervision of the work. W.X. contributed to experimental design, laboratory experiments, and supervision of the work. P.C. contributed to supervision of the work. All authors have read and agreed to the published version of the manuscript.
\end{abstract}

Funding: This work was supported by the National Natural Science Foundation of China [grant number 31971594]; the Natural Science Foundation of the Jiangsu Higher Education Institutions of China [21KJB220009]; the Self-Made Experimental and Teaching Instruments of Nanjing Forestry University in 2021 [nlzzyq202101]; the project from Technology Innovation Alliance of Wood/Bamboo Industry [TIAWBI2021-08]; and the International Cooperation Joint Laboratory for Production, Education, Research, and Application of Ecological Health Care on Home Furnishing.

Data Availability Statement: Not applicable.

Conflicts of Interest: The authors declare no conflict of interest.

\title{
References
}

1. Zhu, J.G.; Wang, X. Research on enabling technologies and development path. J. For. Eng. 2021, 6, 177-183.

2. Sun, Y.; Yu, L.; Ji, G.; Liu, J.Q.; Guo, W. The efficiency analysis on cutting power of EPB shield cutter. Mater. Sci. Forum 2011, 697-698, 706-711.

3. Bo, H.K.; Choi, B.K. Machining efficiency comparison direction-parallel tool path with contour-parallel tool path. Comput.-Aided Des. 2002, 34, 89-95.

4. Hu, W.G.; Guan, H.Y. Experimental and numerical investigation on compression creep behavior of wood. For. Prod. J. 2018, 68, 138-146.

5. Faizrakhmanov, R.A.; Murzakaev, R.T.; Pristupov, V.S.; Polyakov, A.N. Optimization of the energy consumption of a CNC machine cutting tool with hard-to-formalize restrictions. Russ. Electr. Eng. 2017, 88, 701-705. [CrossRef]

6. Lacalle, L.N.L.D.; Fernandez-Larrinoa, J.; Rodriguez-Ezquerro, A.; Fernandez-Valdivielso, A.; Lo'pez-Blanco, R.; AzkonaVillaverde, I. On the cutting of wood for joinery applications. Proc. Inst. Mech. Eng. Part B-J. Eng. Manuf. 2015, $229,940-952$. [CrossRef]

7. Malkoçoğlu, A.; Özdemir, T. The machining properties of some hardwoods and softwoods naturally grown in Eastern Black Sea Region of Turkey. J. Mater. Process. Technol. 2006, 173, 315-320. [CrossRef]

8. Dong, W.; Xiong, X.; Ma, Y.; Yue, X. Woodworking tool wear condition monitoring during milling based on power signals and a particle swarm optimization-back propagation neural network. Appl. Sci. 2021, 11, 9026. [CrossRef]

9. Cao, P.; Zhu, Z.; Guo, X.; Wang, X.; Fu, C.; Zhang, C. Cutting force and cutting quality during tapered milling of glass magnesium board. Appl. Sci. 2019, 9, 2533. [CrossRef]

10. Camposeco-Negrete, C. Optimization of cutting parameters for minimizing energy consumption in turning of AISI 6061 T6 using Taguchi methodology and ANOVA. J. Clean. Prod. 2013, 53, 195-203. [CrossRef]

11. Zhu, Z.; Buck, D.; Guo, X.; Cao, P.; Wang, J. Cutting performance in the helical milling of stone-plastic composite with diamond tools. CIRP J. Manuf. Sci. Technol. 2020, 31, 119-129. [CrossRef]

12. Zhu, Z.; Buck, D.; Guo, X.; Cao, P. High-quality and high-efficiency machining of stone-plastic composite with diamond helical cutters. J. Manuf. Process. 2020, 58, 914-922. [CrossRef]

13. Chaharmahali, M.; Tajvidi, M.; Najafi, S.K. Mechanical properties of wood plastic composite panels made from waste fiberboard and particleboard. Polym. Compos. 2008, 29, 606-610. [CrossRef]

14. Tabarsa, T.; Khanjanzadeh, H.; Pirayesh, H. Manufacturing of wood-plastic composite from completely recycled materials. Key Eng. Mater. 2011, 471-472, 62-66.

15. Jayaraman, K.; Bhattacharyya, D. Mechanical performance of woodfibre-waste plastic composite materials. Resour. Conserv. Recycl. 2004, 41, 307-319. [CrossRef]

16. Cai, C.; Haapala, A.; Rahman, M.H.; Tiitta, M.; Tiitta, V.; Tomppo, L.; Lappalainen, R.; Heräjärvi, H. Effect of two-year natural weathering on chemical and physical properties of thermally modified Picea abies, Pinus sylvestris and Fraxinus excelsior wood. Can. J. For. Res. 2020, 50, 1160-1171. [CrossRef]

17. Soury, B.; Esfahani, A.H.; Zolfaghari, Z.R. Design, optimization and manufacturing of wood-plastic composite pallet. Mater. Des. 2009, 30, 4183-4191. [CrossRef]

18. Association CFI. Floor sales in China in 2020. China Wood-Based Panels 2021, 28, 47.

19. Guo, X.; Wang, J.; Buck, D.; Zhu, Z.; Guo, Y. Machinability of wood fiber/polyethylene composite during orthogonal cutting. Wood Sci. Technol. 2021, 55, 521-534. [CrossRef]

20. Pei, Z.; Zhu, N.; Gong, Y. A study on cutting temperature for wood-plastic composite. J. Thermoplast. Compos. Mater. 2016, 29, 1627-1640. [CrossRef] 
21. Zhao, Z.; Sun, S.; Wu, D.; Zhang, M.; Huang, C.; Umemura, K.; Yong, Q. Synthesis and characterization of sucrose and ammonium dihydrogen phosphate (SADP) adhesive for plywood. Polymers 2019, 11, 1909. [CrossRef] [PubMed]

22. Guo, X.; Ekevad, M.; Marklund, B.; Li, R.; Cao, P.; Grönlund, A. Cutting forces and chip morphology during wood plastic composites orthogonal cutting. Bioresources 2014, 9, 2090-2106. [CrossRef]

23. Li, R.R.; He, C.J.; Wang, X.D. Evaluation and modeling of processability of laser removal technique for bamboo outer layer. JOM 2021, 73, 2423-2430. [CrossRef]

24. Li, R.R.; Chen, J.; Wang, X.A. Prediction of the color variation of moso bamboo during $\mathrm{CO}_{2}$ laser thermal modification. Bioresources 2020, 15, 5049-5057. [CrossRef]

25. Lu, F.; Jian, Z.; Xiaomei, L.; Yuanyuan, Z.; Jialing, S. Tensile shear strength and microscopic characterization of veneer bonding interface with polyethylene film as wood adhesive. Sci. Adv. Mater. 2019, 11, 1223-1231.

26. Li, R.; Fang, L.; Xu, W.; Xiong, X.; Wang, X.A. Effect of laser irradiation on the surface wettability of poplar wood. Sci. Adv. Mater 2019, 11, 655-660. [CrossRef]

27. Li, R.R.; Yao, Q. Research on equipment configurations of the flexible production line for intelligently manufacturing customized panel furnitures. Chin. J. Wood Sci. Technol. 2021, 35, 23-29.

28. Oda, Y.; Mori, M.; Ogawa, K.; Nishida, S.; Fujishima, M.; Kawamura, T. Study of optimal cutting condition for energy efficiency improvement in ball end milling with tool-workpiece inclination. CIRP Ann. 2012, 61, 119-122. [CrossRef]

29. Barcík, Š.; Pivolusková, E.; Kminiak, R. Effect of technological parameters and wood properties on cutting power in plane milling of juvenile poplar wood. Drv. Ind. 2008, 59, 107-112.

30. Fernández-Abia, A.I.; Barreiro, J.; de Lacalle, L.N.L.; Martínez-Pellitero, S. Behavior of austenitic stainless steels at high speed turning using specific force coefficients. Int. J. Adv. Manuf. Technol. 2012, 62, 505-515. [CrossRef]

31. Zhao, Z.Y.; Miao, Y.F.; Yang, Z.Q.; Wang, H.; Sang, R.J.; Fu, Y.C.; Huang, C.X.; Wu, Z.H.; Zhang, M.; Sun, S.J.; et al. Effects of sulfuric acid on the curing behavior and bonding performance of tannin-sucrose adhesive. Polymers 2018, 10, 651. [CrossRef] [PubMed]

32. Mandic, M.; Todorovic, N.; Popadic, R.; Danon, G. Influence of wood properties and technological parameters of processing on cutting power in milling of thermally modified beechwood. Bull. Fac. For. 2011, 104, 109-124. [CrossRef] 